\title{
Moral identification in Identity Management Systems
}

\author{
Noëmi Manders-Huits and Jeroen van den Hoven
}

\author{
Department of Philosophy, \\ Delft University of Technology, Netherlands \\ N.L.J.L.Manders-Huits@tudelft.nl \\ M.J.vandenHoven@tudelft.nl
}

\begin{abstract}
Identity has become a central theme in modern philosophy. In this paper we are not concerned with the logic and metaphysics of identity, nor with questions of personal identity. We address a part of the ethics of identity in the light of ubiquitous modern technologies of identity management. In many practical contexts it is a 'forensic' and 'biographical' notion of identity and identification that is often prominent and morally problematic. Persons identify themselves and are identified by others; they present themselves as having certain properties, others scrutinize their self-presentations and form alternative representations of them, either in- or outside formal or administrative systems. Persons are consequently dealt with in legal and administrative contexts (and increasingly also in private spheres) on the basis of formal representations and sets of characteristics or statistical profiles. In this paper we articulate a basic moral justification for constraints on how persons may be represented and identified in identity management systems by explicating Bernard Williams' suggestion that respect for persons implies a particular form of identification, which we term "moral identification". Moral identification in this sense implies the identification of a person as someone who engages in self-identification.
\end{abstract}

\section{Introduction ${ }^{1}$}

There is an increasing need for identification and identity management. Globalization, mobility, and international terrorism have recently added to the desire of many to be clear about individual identities in order to know "who is who" on the internet, on the road, at airports, and in business transactions. Considerable investments are being made by governments and businesses around the world to unambiguously establish identities of citizens and customers and to learn as much as possible about them. Both in the public and in the private sector "identity management technologies" are used for that purpose. They allow one to manage identities of persons in two different

${ }^{1}$ This article builds upon previous work by the authors, i.e. Manders-Huits en Van den Hoven, 'Het Managen van Identiteiten en Morele Identificatie', Algemeen Nederlands Tijdschrift voor Wijsbegeerte, 98 (2), 111-128 (2006).

Please use the following format when citing this chapter:

Manders-Huits, N. and van den Hoven, J., 2008, in IFIP International Federation for Information Processing, Volume 262; The Future of Identity in the Information Society; Simone Fischer-Hübner, Penny Duquenoy, Albin Zuccato, Leonardo Martucci; (Boston: Springer), pp. 77-91. 
senses. First, they manage the access of persons to physical spaces, to knowledge, information and communication infrastructures and to a broad range of services. They do so on the basis of the identity of individuals and their associated authorizations for access. Secondly, identity management technologies enable the storage of elaborate digital representations of individuals in databases for a broad range of uses. Individuals are now increasingly treated on the basis of these representations; The treatment they receive, the things they are entitled to, their rights, accountabilities, the opportunities they are given and the limitations that are imposed upon them are shaped by the way their identities are construed and used. The example of an identity management system used in this paper is the Electronic Health Record that is being developed in the Netherlands for regulating data streams between caregivers in the health sector. ${ }^{2}$ There are also numerous databases and future (commercial) identity management systems which collect and store data for various purposes, including some not yet envisioned.

Hundreds of agencies and thousands of databases in the Western World and in the East (e.g., as a result of off-shoring in the world of medical image processing) keep files on citizens in the West. The digital representations of them are assumed to be good enough for a rapidly growing number of practical purposes. More and more often organizations act upon what a record, a file, a data set or a profile leads them to believe about a particular person. Categories, descriptions and models are routinely imposed on individuals' identity information. We know what dramatic consequences the availability of labels like 'Jew', 'Hutu' and 'Tutsi' and 'white', 'black' , 'honorary white', 'colored people' in administrative identity management systems can have for those concerned. In political, military and racial conflicts, but also in everyday practices in the insurance and the financial world, profiles, postal codes, income data, educational records, and a wide variety of behavioral indicators are used to sort and classify people [1,2].

Neuro-images, genetic information and other biometric data may in the future be included as an annex to the biography of individuals or even directly linked to computer networks, architectures and databases. Government agencies understandably want to know who the tax evader is, who the serial rapist is, and who has a tendency to become one, but also - on a more positive note - they want to know who is among worst off in society and in need of assistance or services.

In this paper we set out to articulate moral reasons for constraining the management of identity by others than the person whose identity is at stake. What do we owe to people when we are dealing and tinkering with their identities by representing them, changing their representations and self-presentations, or acting on the basis of these representations? In the first half of the paper we will discuss what kind of identity we are talking about in identity management. Next, we discuss the shortcomings of thinking about personal data and the protection thereof in light of the possibilities of modern identity management. We claim that it is necessary to extend

${ }^{2}$ This identity management system is carefully designed for a specific purpose, confining the span of control over data to the health domain. Our argument, needless to say, is on a more general level towards identity management systems. Therefore the example may not cover our argument in full depth, though it will illustrate our main point. 
the category of data worthy of protection in relation to persons and their identity in two directions and we therefore prefer to speak of "identity related data" instead of "personal data". In the first place identity related data does not need to be linked to specific natural persons to be worthy of protection, as most discourse and legislation concerning the protection of personal data presupposes. Identification in a morally relevant sense can occur without the referential use of descriptions. Descriptions need neither be tied to the perception of individuals. Even without a unique reference and linkage to specific individuals there can be practically relevant and important strategies to get to know more about persons, whoever they may be and to structure interaction with them in an electronic environment accordingly. This is what is morally relevant.

In the second half of the paper we will give four reasons for the protection of identity related data in this broader sense. The fourth moral reason, pertaining to moral autonomy, implies epistemic modesty with respect to knowing the identity of persons and respect for persons as "self-presenters". This moral consideration leads up to the formulation of the demand for "moral identification" as put into words by Bernard Williams.

\subsection{The Electronic Health Record ${ }^{3}$}

An example of an identity management system now being developed is the Electronic Health Record in The Netherlands. Ministries, government agencies and others are working on a national identity management system - as is the case in many other countries - that will enable caregivers to share patient data via electronic communication. Different health organizations can add and exchange health related data using a pointer system, the National Switch Point (LSP), routing and authorizing data demands. This information is kept and filed under a national identification number, the Citizen Service Number4. Although the design of this identity management system is still ongoing and the architecture hasn't yet reached its final form, it can be assumed from pilot tests that are now being done that the architecture will be designed handling data in a decentralized way and providing patients appropriate control over their own data. The Electronic Health Record will be individually accessible for patients, e.g. by using their Citizen Service Number in combination with a personal code. As we will argue, 'moral identification', the moral concern with identity management discussed in this paper, is something to be kept in mind when completing the design of this particular identity management system.

\footnotetext{
${ }^{3}$ In Dutch: Elektronisch Patiënt Dossier (EPD), for more information see http://www.minvws.nl/images/fo-dutch-approach_tcm20-146105.pdf

${ }^{4}$ In Dutch: Burger Service Nummer (BSN)
} 


\section{Biographical identity}

Identity management, in the sense given above, is concerned with 'identity' and 'identification' in a practical, biographical or forensic sense. John Perry calls the biographical and the forensic elements of our identity "objective representations" of persons. They are called objective since there is nothing that makes their content depend on who created them: they do not necessarily contain expressions with the first person pronoun "I". Some of these representations cannot be changed by the person, e.g. address or nationality. Take for instance Rip Van Winkle, an old Dutch Settler who falls asleep in the mountains before the American revolution. He wakes up twenty years later, after the revolution, and upon his return in the village he claims to be loyal to the British King, without realizing he is American Citizen now.

David Velleman [3] argues that these representations of persons are often and in part self made, in which case he refers to them as the "self-images" that persons present. Self-images are just among a number of different aspects or guises of selves. By means of a self-image "a person represents which person and what kind of person he is-(...) how he looks, what he believes in, what his personality is like, and so on". Velleman thinks, like Perry, that this self-image is not intrinsically reflexive, since "it picks out the one he is, thus identifying him with one of the world's inhabitants". It is a way of conceiving of oneself as the potential referent of the pronoun 'who', which ranges over persons in general". It is the representation of a person "considered nonfirst-personally but identified as the subject by some other, extrinsic means".[3]

Identity management does not only concern objective representations, but also concerns unique references to persons by means of descriptions proper names, passwords, personal ID-numbers and user names. We use these descriptions even if we don't know the person or do not see the person, when there are no de re-thoughts. According to John Perry and Kent Bach thinking of a person by means of a description or name should be reconstrued in terms of "calling up a file on that individual'.[4,5] They give a description of "singular reference" in terms of so-called "files". Perry argues that we receive information on an individual from within a role. Objects and persons can play an "agent relative" role in someone's life, for instance by "standing in front of someone" or "being on the phone with someone". Epistemic and pragmatic methods are attached to these "agent relative" roles, e.g. "methods for finding out about the object and methods for doing things to the object (...), the success of which depends on facts about the object'.[4] Introducing yourself to someone and shaking that person's hand is an example of applying the information that is attached to the "being in front of someone"-role and what coordinates acting. This is part of the standard information game that people play.

Another important activity in this respect is referred to by Perry as the "detach and recognize information game". Perry gives an example of a business card, but another example could be the checking of a municipal database a "customer relationship database" on the laptop of a travelling sales man or the electronic patient health records of a local hospital. When someone hands over his or her business card, the objective representations on the card (such as name, address, profession, birth date, resume, etc.) are tied/linked to a person.. When one is no longer together, the 
objective representations are separated from perception. The next time one meets this person again, one can re-attach the information to a perception, recognize the person from the card and re-apply one's own convictions about this person. This procedure of separation and recognition is crucial for communication where separated information is exchanged in a way in which others can re-attach their own perceptions to this person or object'. The objective representations and their separated supplement are "agent relative" perceptual ways of thinking and acting. Perry stresses that 'an objective representation with no possibility of being reattached to its source via some agent-relative role that supports pragmatic techniques is quite useless'.[4]

\section{Identity related information and data protection constraints}

Descriptive phrases can be said to form partial identities in the sense that they can all figure in tags or contents of mental, physical or electronic files on people: "The man next door", "my best colleague", "the guy with the awful aftershave", "John", "John Smith", "the guy who always takes the 9 o'clock train and gets off at central station", "the owner of a blue ford", "the person who collected 200 Euro at the teller machine in the Centre of Amsterdam at 14:21:11 at August 1 2005", "the person on the cctv tape who put two orange boxes in the trunk of a blue Ford", "the owner of a bank account 1234567", "the person on Flight Q1 from Sydney to London on October 2 2005 in seat 55c", "the idiot with the baseball cap", "the guy who dumped Alice". These description could all be about different persons, they could also be about the same person (in which case the characterizations provide already a lot of information about John Smith), or they could fail to refer, since there is no one who satisfies this list of properties.

Keith Donellan distinguished between referential use of descriptions and attributive use of descriptions. "The owner of a blue ford living in postal code area 2345 " could have more than one individual satisfying the description and the user of these descriptions may not have a particular individual in mind; he just thinks about the owner of a blue Ford "whoever he is'. "The owner of a blue Ford" could also be used referentially, when we have a particular person in mind or in attendance. "The man sipping his whisky" (pointing to the person at a party) is used referentially, and is about the person the speaker mistakenly thought was drinking whisky, even when it turns out he is actually having ice-tea instead of whisky, and there is, strictly speaking, no one over there sipping his whisky.

Both attributively used and referentially used descriptions figure in epistemic and doxastic strategies to collect information on people and to expand our knowledge and belief sets on them. Both represent identity relevant information. One may open a mental or another type of file on a person under the label "the murderer of Kennedy", as crime investigators do. The history of their criminal investigation is at the same time the history of filling the file with identity relevant information. The police has a good deal of freedom to fill the files on suspects and establishes the identity of the criminal. They can use biometric techniques such as fingerprinting, DNA evidence, 
Internet traffic data, they can use logistic and travel data, Closed Circuit Television tapes, stories told by eye witnesses and combinations of these.

The moral and legal constraints in the data-protection and privacy laws and regulations that are in place all over the world apply primarily to referentially used descriptions of persons. It should be clear however that both usages of descriptions can play an important role in keeping tabs on people and in managing their identities. The international laws on privacy and data-protection define personal data as follows [6]:

"'personal data' shall mean any information relating to an identified or identifiable natural person ('data subject'); an identifiable person is one who can be identified, directly or indirectly, in particular by reference to an identification number or to one or more factors specific to his physical, physiological, mental, economic, cultural or social identity"

The referential reading of 'identity' and 'identifiable' leads to an unduly narrow construal of moral constraints on identity management techniques. and attributively used descriptions could go unprotected. This seems a major weakness of data protection regimes, since we know that large amounts of data are used attributively, in marketing, security and profiling domains for example. One could have a file on an owner of a blue Ford, and add a long list of descriptions, all used attributively. Adding one piece of information to the rich and anonymous file could suddenly make the data set uniquely referring. Consider Ruth Gavison's anecdote in her article "Privacy and the Limits of Law"'7]:

"Consider the famous anecdote about the priest who was asked, at a party, whether he had heard any exceptional stories during confessionals. "In fact", the priest replied, "my first confessor is a good example, since he confessed to murder". A few minutes later, an elegant man joined the group, saw the priest, and greeted him warmly. When he asked how he knew the priest, the man replied: "Why, I had the honour of being his first confessor".

Did the priest violate the privacy of the elegant man? Gavison thinks that the first piece of information was anonymous and did not violate the confessor's privacy in and by itself. The second piece was about a specific individual, but was volunteered by the person whose privacy is at stake and could therefore also not have violated the man's privacy. Gavison however claims that the latter piece of information "turned what was previously an anonymous piece of information into further information about the individual" [7]: there is "a translation from anonymous information to information about X"

Gavison presents this anecdote in the context of a listing of problems associated with the clarification of the notion of privacy. It all starts with the requirement "that for a loss of privacy to occur, the information must be "about" the individual.

It may well be the case that given the prominence and importance of identity management techniques and technology we need to have a new look at this requirement and instead of defining the object of protection in terms of referentially used descriptions, we need to define the object of protection in terms of the broader notion of "identity relevant information", even if it is not 'about' a particular person, 
since we know it can be equally useful as a part of an epistemic strategy or doxastic policy to get to know more about particular individuals eventually.

Perry focused on recognition and the importance of reattachment of objective representations to some perception, preparing the information for use ("recognition is a prelude to action"). In recognition, according to Perry, a comparison takes place between the attributes of the person perceived with the attributes of the person one has on file. No matter how vast the files and records and detached objective representations are, since all perception and action takes place by agents at certain times, they need to be (re)attached to perceptions.

This seems again to point in the direction of another narrow construal of the scope of moral constraints on identity management techniques and technology. Recognition may also take place on the level of files of beliefs regarding detached representations, without them being necessarily tied to perceptions. Think e.g. of an insurance agent, who is handling and evaluating insurance declarations. He knows the dossiers, numbers, and names and is looking at a case of a stolen bicycle in one of the big cities. During his lunch break he suddenly realizes that this very same person has had his bicycle stolen last year. The identities our insurance clerk processes are descriptions or objective representations, detached, but the most relevant form of recognition does not seem to require reattachment by him to a perception. As a matter of fact many of the acts of recognition and (re)identification in information rich work environments dealing with identities of individuals are about detached representations which are unlinked to any perception of the data subject.

Many acts of identification in the field relevant for identity management involve descriptions that are used attributively and do not involve re-attachment in Perry's sense.

They are attempted identifications of whoever satisfies the description, without ever being in a position to attach or reattach this in a perceptual context to a particular person. Still these identifications play an important role in epistemic strategies and doxastic policies to learn about persons. We need to think about the moral constraints that may apply to these new practices.

\section{Data protection from the perspective of moral autonomy}

We will now discuss four types of moral reasons for constraining the management of identity relevant information.

\subsection{Information-Based Harm}

The first type of moral reason for thinking about constraining identity management by others is concerned with the prevention of harm, which is done to persons by making use of identity related information. Cyber criminals and malevolent hackers are known to have used computerized databases and the Internet to get information on their victims in order to prepare and stage their crimes. One of the most important 
moral problem is 'identity theft' and identity Fraud, with brings high risk of financial damages and emotional distraught. One's bank account may get plundered and one's credit reports may be irreversible tainted so as to exclude one from future financial benefits and services. Stalkers and rapists have used the Net and on-line databases to track down their victims and they could not have done what they did without tapping these electronic resources and finding out about some of the most intimate details of their victim's lives. In the information society there is a new vulnerability to harm done to one on the basis of identity -theft, identity fraud or straightforward harm using identifying information. Justifications of constraining the freedom of persons who cause, threaten to cause, or are likely to cause, harms to people using identity related information can be justified by invoking Mill's Harm Principle [8]. Protecting identifying information, instead of leaving it in the open, diminishes the likelihood that people will come to harm, analogous to the way in which restricting access to fire arms diminishes the likelihood that people will get shot in the street. In information societies, identity relevant information resembles guns and ammunition.

\subsection{Informational Inequality}

The second type of moral constraint on identity related information is concerned with equality and fairness. More and more people are keenly aware of the benefits the market for identity information can provide them. If a consumer buys coffee at the modern shopping mall, information about that transaction is generated and added to his file or profile. Many consumers now begin to realize that every time they come to the counter to buy something, they can also sell something, namely, the information about their purchase or transaction, the so-called transactional data. Likewise, sharing information about ourselves on the Net with web sites, browsers, and autonomous agents may pay off in terms of more and more adequate information (or discounts and convenience) later. Many privacy concerns have therefore been and will be resolved in quid pro quo practices and private contracts about the use and secondary use of personal data. But although a market mechanism for trading personal data seems to be kicking in on a global scale, not all individual consumers are aware of this economic opportunity, and if they do, they are not always able to trade their data in a transparent and fair market environment, so as to get a fair price for them. Moreover they do not always know what the implications are of what they are consenting to when they sign a contract. We simply cannot assume that the conditions of the developing market for identity related information guarantees fair transactions by independent standards. Constraints for Identity Management need to be put in place in order to guarantee equality and a fair market for identity relevant information.

\subsection{Informational Injustice}

A third and very important moral reason to justify constraints on identity management by others is concerned with justice in a sense which is associated with the work of Michael Walzer. Michael Walzer has objected to the simplicity of Rawls' conception 
of primary goods and universal rules of distributive justice by pointing out that "there is no set of basic goods across all moral and material worlds, or they would have to be so abstract that they would be of little use in thinking about particular distributions" [9]. Goods have no natural meaning; their meaning is the result of socio-cultural construction and interpretation. In order to determine what a just distribution of the good is we have to determine what it means to those for whom it is a good. In the medical, the political, the commercial sphere, there are different goods (medical treatment, political office, money) which are allocated by means of different allocation or distributive practices: medical treatment on the basis of need, political office on the basis of desert and money on the basis of free exchange. What ought to be prevented, and often is prevented as a matter of fact, is dominance of particular goods. Walzer calls a good dominant if the individuals that have it, because they have it, can command a wide range of other goods [9]. A monopoly is a way of controlling certain social goods in order to exploit their dominance. In that case advantages in one sphere can be converted as a matter of course in advantages in other spheres. This happens when money (commercial sphere) could buy you a vote (political sphere) and would give you preferential treatment in healthcare (medical), would get you a university degree (educational), etc. We resist the dominance of money -and other social goods for that matter (land, physical strength) - and we think that political arrangements allowing for it are unjust. No social good $\mathrm{x}$ should be distributed to men and women who possess some other good y merely because they possess $y$ and without regard to the meaning of $x$.

What is especially offensive to our sense of justice is the allocation of goods internal to sphere $A$ on the basis of the distributive logic associated with sphere $B$, second, the transfer of goods across the boundaries of separate spheres and thirdly, the dominance and tyranny of some goods over others. In order to prevent this from happening the 'art of separation' of spheres has to be practiced and 'blocked exchanges' between them have to be put in place [9]. If the art of separation is practiced effectively and the autonomy of the spheres of justice is guaranteed then 'complex equality' is established. One's status in terms of the holdings and properties in one sphere are irrelevant -ceteris paribus- to the distribution of the goods internal to another sphere.

Walzer's analysis also applies to information. The meaning and value of information is local, and allocation schemes and local practices that distribute access to information should accommodate local meanings and should therefore be associated with specific spheres. Many people do not object to the use of their personal medical data for medical purposes, whether these are directly related to their own personal health affairs, to those of their family, perhaps even to their community or the world population at large, as long as they can be absolutely certain that the only use that is made of it is medical, i.e. to cure people from diseases. They do object, however, to their medical data being used to classify them or disadvantage them socio-economically, to discriminate against them in the workplace, refuse them commercial services, deny them social benefits, or turn them down for mortgages or political office on the basis of their medical records. They do not mind if their library search data are used to provide them with better library services, but they do mind if 
these data are used to criticize their tastes, and character. They would also object to these informational cross-contaminations when they would benefit from them, as when the librarian would advise them a book on low-fat meals on the basis of knowledge of their medical record and cholesterol values, or when a doctor asks questions on the basis of the information that one has borrowed a book from the public library about AIDS.

We may thus distinguish a third moral reason to constrain identity management: "informational injustice", that is, disrespect for the boundaries of what we may refer to, following Michael Walzer, as 'spheres of justice' or 'spheres of access'. I think that what is often seen as a violation of privacy is oftentimes more adequately construed as the morally inappropriate transfer of personal data across the boundaries of what we intuitively think of as separate "spheres of justice" or "spheres of access."

\subsection{Moral autonomy}

Even though there are multiple reasons to support data protection, in this paper we focus on moral autonomy - and especially moral identification. It is argued by some that privacy is a necessary condition for (the development of) moral autonomy [10]. It provides a safe place as well as the freedom to experiment in order to develop and protect a personal identity. The development and continuous adaptation of who we want to be and who we want to become are both fundamental to and expressions of our moral autonomy.

We argue that moral autonomy, i.e. the capacity to shape our own moral biographies, to reflect on our moral careers, to evaluate and identify with our own moral choices, without the critical gaze and interference of others and a pressure to conform to the 'normal' or socially desired identities, is one of the moral reasons for constraining identity management by others. A moral person is engaged in selfdefinition and self-improvement, and experiences the normative pressures which public opinion and moral judgements of others exert on the person to conform to a socially desired identity. Information about Bill, whether fully accurate or not, facilitates the formation of judgements about Bill. Judgements about Bill, when he learns about them, when he suspects that they are made, or fears that they are made, may bring about a change in his view of himself, may induce him to behave and feel differently than he would have done without them.

To modern contingent individuals, who have cast aside the ideas of historical necessity, living in a highly volatile socio-economic environment, and a great diversity of audiences and settings before which they make their appearance, the fixation of one's moral identity by means of the judgements of others is felt as an obstacle to 'experiments in living' [8], as Mill called them. This is what happens when one is applying for a job and confronted with - possibly even judged or prescreened on the basis of - personal experiments on the Internet, by means of chat boxes, You Tube videos, gaming and other activities that pop up when 'googled ${ }^{5}$ by the potential employer. Or, in the case of the Electronic Health Record, data is stored

\footnotetext{
${ }^{5}$ Term used in popular everyday language referring to the use of the Google search engine (www.google.com) to get to know more about a person (or subject).
} 
in the record and directly retrievable revealing preferences of the past that one does not (fully) support any longer or wishes to be associated with, e.g. a visit to the general practitioner concerning the treatment of an infected piercing.

The modern individual wants to be able to determine himself morally or to undo his previous determinations, on the basis of more profuse experiences in life, or additional factual information. As Newton Garver aptly put it:

Contemporary freedom and choice go farther than Mill suspected - we all chose our identities, and make that choice from among a heterogeneous set of data, (...) we rarely choose our nationality, sex or religion, but we do choose to make these data part of our identity"[11]

The conception of the person as being morally autonomous, as being the author and experimenter of his or her own moral career, provides a justification for constraining others in their attempts to engineer and directly or indirectly shape the subjects identity. The fixation of one's moral identity by others than oneself should be prevented in the design of identity management systems and their regulatory framework. This is done by holding on to the requirement of informed consent and notification for the processing of the individual's data. If there are domains where for obvious reasons individuals in well-ordered societies cannot be allowed to write their own biographies from cover to cover, they at least should be allowed to write those parts that are amenable to it and to be given an opportunity to authorize the parts that were or had to be written by others.

For the example that we use of the Electronic Health Record, this works out as follows: Patients should be notified and/or asked for their consent when adding/collecting/processing their data in the system. Moreover, they should have individual access in order to control what information is being kept so that they can become aware what the possible implications of data exchange may be. Imagine for example cases where sensitive information regarding psychological health or birth control is available and accessible. The fixation of one's moral identity could concern categories such as: 'depressed', 'accident prone', 'unstable', 'hysterical', 'quarrelsome' or 'promiscuous', but also risk categories concerning a particular disease.

\subsection{Moral identification}

In his analysis of privacy and shame, Velleman states that individuals have a fundamental stake 'in being recognized as a self-presenting creature, an interest that is more fundamental, in fact, than your interest in presenting any particular public image'.[12] Events can be shameful for someone if the person in question is not able to present him- or herself as he or she wishes. This undermines his or her status as a self-presenting individual.[12] 'When something private about you is showing, you have somehow failed to manage your public image, and so an inadequacy in your capacity for self-presentation is showing as well, potentially undermining your standing as a social agent'.[12] Privacy norms are - according to Velleman implicitly 'norms of competence at self-presentation'.[12] 
This is also the case with victims of stereotyping: they are being characterized in a way 'that leaves no room for self-presentation.'[12] Someone being characterized for example on the basis of ethnicity, doesn't have to feel ashamed because of his or her (ethnic) background, but rather because he or she feels represented as 'less than the master of his self-definition and therefore less than a socially qualified agent.'[12] Shame is 'the anxious sense of being compromised in one's self-presentation in a way that threatens one's social recognition as a self-presenting person.'[12] Velleman's analysis of shame suggests that interventions in the identity management and selfpresentation of a person by others can compromise the status of a person as a social agent.

A further explanation for the importance of respect for moral autonomy may be provided along the following lines. Factual knowledge of one person by another is always knowledge by description. The person himself however, does not only know the facts of his biography, but is the only person who is acquainted with the associated thoughts, desires, emotions and aspirations. However detailed and elaborate our files and profiles on Bill may be, we are never able to refer to the data-subject as he himself is able to do. We may only approximate his knowledge and selfunderstanding.

Bernard Williams has pointed out that respecting a person involves 'identification' in a very special sense, which we refer to as 'moral identification'.

"(...) in professional relations and the world of work, a man operates, and his activities come up for criticism, under a variety of professional or technical titles, such as 'miner or 'agricultural labourer' or 'junior executive'. The technical or professional attitude is that which regards the man solely under that title, the human approach that which regards him as a man who has that title (among others), willingly, unwillingly, through lack of alternatives, with pride, etc. (...) each man is owed an effort at identification: that he should not be regarded as the surface to which a certain label can be applied, but one should try to see the world (including the label) from his point of view"[13].

Moral identification thus presupposes knowledge of the point of view of the datasubject and a concern with what it is for a person to live that life. Persons have aspirations, higher order evaluations and attitudes and they see the things they do in a certain light. Representation of this aspect of persons seems exactly what is missing when personal data are piled up in our data-bases and persons are represented in administrative procedures; compare the categories one can be assigned to by combining health data from the Electronic Health Data without the appropriate contextual data.

The identifications made on the basis of data on persons fall short of respecting the individual person, because they will never match the identity as it is experienced by the data-subject. It fails because it does not conceive of the other on his own terms. Respect for privacy of persons can thus be seen to have a distinctly epistemic dimension. It represents an acknowledgement that it is impossible to really know other persons as they know and experience themselves. Even if we could get it right about moral persons at any given point in time, by exhibit of extraordinary empathy and attention, then it is highly questionable whether the data-subject's experience of 
himself, as far as the dynamics of the moral person is concerned, can be captured and adequately represented. The person conceives of himself as trying to improve himself morally. The person cannot be identified, not even in the sense articulated by Bernard Williams, with something limited, definite and unchanging. This point was by the French existentialist Gabriel Marcel:

“(...) a person should definitely not in any way be compared to an object, which we can say is there, i.e., is given and present before us, and is part of an inherently denumerable collection, or even is a statistical element $(. .). "[14]^{6}$

The person always sees itself as becoming, as something that has to be overcome, not as a fixed reality, but as something in the making, something that has to be improved upon:

"The person sees him- or herself much less as a being than as a will to transcend the totality of what he or she is and is not, i.e., a reality which he or she feels genuinely committed to and involved in but which fails to satisfy her, because it falls short of the aspirations he or she identifies with" $[14]^{7}$.

As Marcel puts it, the individual's motto is not sum ( $\mathrm{I}$ am) but sursum (higher). The human person has a tendency not to be satisfied, but he or she is always aspiring to improve him or herself. Always on his or her way, Homo Viator. This is also suggested by Berlin: "what I may seek to avoid [is to be] insufficiently recognized,... a statistical unit without identifiable ... purposes of my own."[15] Because we feel we have inaccessible qualitative aspects of our own private mental states, i.e. that we have hopes and purposes and there is something that it is like to have them, which cannot be known from the outside, we insist on epistemic modesty on the part of others in claiming to know who we are or to be actively involved in the management of our identities. Moreover, we see ourselves as our own moral projects, subject to moral development and capable of moral improvement, so the result of the management of our identities seems a premature fixation of what is an essentially dynamic project.

Respect for persons in the field of identity management involves epistemic modesty in explicit or implicit claims to know who someone is. Individuals resist quite understandably the pretense which seems to be ingrained in the identity management technology and implied in its very idea, to the effect that they can be fully known.

"...the apprehension of the mind of another person may thus only count as knowledge to the extent that it can approximate to this kind of awareness... such an approximation can never be more than a very distant one."[16]

${ }^{6}$ Translated by Manders-Huits. Original quote: “(...) il faudra dire que la personne ne saurait être assimilée en aucune maniere a un objet dont nous pouvons dire qu'il est la, c'est-a-dire qu'il est donne, present devant nous, qu'il fait partie d'une collection par essence denombrable, ou encore qu'il est un element statistique (...)".

${ }^{7}$ Translated by Manders-Huits. Original quote: "Elle se saisit bien moins comme etre que comme volonte de depasser ce que tout ensemble elle est et elle n'est pas, un actualite dans laquelle elle se sent a vrai dire engagee ou implique, mais qui ne la satisfait pas: qui n'est pas a la mesure de l'aspiration avec laquelle elle s'identifie". 
When a person is considered as 'one person among others', his attitude and selfdirected reactive attitudes (his shame or shamelessness) expresses the kind of person he is. It is the sort of thing we take into account in determining how we feel about him. Moran argues that not doing so would be wrong since it would be failing to respect the "total evidence" of the case. For responding to what he did with shame, pride or gratitude constitutes a new facts about him, which are morally salient and provide part of the total evidence of who he is. Anything less would not only be wrong, but also epistemically irresponsible [16].

\section{Conclusion}

Through the availability of information technology identities of persons have become objects of manipulation by others than the ones whose identity is at stake. We have argued that all identity related data, also when it concerns descriptions that are not used referentially, but attributively, or descriptions which are not reducible to a unique and perceivable natural person, is worthy of protection and access should be made dependent of the informed consent by the person in question.

We have articulated four moral reasons for the justification of this protection. Constraining the freedom of others to assimilate, process or aggregate data can be justified on the basis of the following considerations: (1) the prevention of harm to the person or data subject, (2) fairness and transparency in the market of identity related data, (3) the separation of social spheres where identity related data has different connotations and practical meanings, and (4) moral autonomy.

Respect for moral autonomy in the meaning defined by us, implies (a) epistemic modesty in knowledge based claims about persons and (b) respect for persons as "self-presenters". The pretense which seems to be ingrained in identity management technologies and implied in the very idea thereof, to the effect that the identity of persons can be fully known, quite understandably stirs up resistance of data subjects involved who appeal against this epistemic arrogation, often by appealing to his or her "privacy".

Therefore, where we cannot leave it completely up to individuals to write their own autobiographies and design their own identities in identity management systems, since some facts about individuals need to be standardized and cannot be under the control of the subject, we argue that they have a right to authorize and correct, when and where appropriate. Moreover, the parts of individuals' identities that need to be managed by others for reasons alluded to above, require not only careful and thorough identification strategies for the sake of accuracy and completeness, but also require attempts at 'moral identification' in Williams' sense. Returning to the example of the Dutch Electronic Health Record, we endorse that patients are to be given the opportunity of control over their data as intended. They should be encouraged to verify and manage their data, in order to keep control over their (perceived) identities and to prevent the patients as persons in this identity management system to become patients as numbers. 


\section{Acknowledgements}

I wish to thank Bjørn Jespersen for assisting with French translation and Michael Zimmer for commenting on earlier drafts of this paper. I also thank the faculty and students attending the IFIP Summer School for their valuable feedback.

\section{References}

1. O. Gandy, The Panoptic Sort, (Westview, Boulder (Colorado), 1993)

2. O. Gandy, 'Dividing practices: segmentation and targeting in the emerging public sphere' in Lance Bennett \& Robert Entman (eds), Mediated Politics: Communication in the Future Democracy, (Cambridge University Press, New York, 141-159, 2001)

3. D. Velleman, Self to Self. Selected Essays, (Cambridge University Press, Cambridge, 2006)

4. J. Perry, Identity, Personal Identity and the Self, (Hackett, Indianapolis, 2002)

5. K. Bach, Thought and Reference, (Oxford University Press, Oxford, 1987)

6. Directive 95/46/EC on 'The protection of individuals with regard to the processing of personal data and on the free movement of such data', (Official Journal L 281, pp. 31-50, Brussels, 1995)

7. R. Gavison, 'Privacy and the Limits of Law', in F. Schoeman (ed.) Philosophical Dimensions of Privacy, (Cambridge: Cambridge University Press, 346-402, 1984)

8. J.S. Mill, On Liberty, edited by H.B. Acton (Everyman edition, London, 1972)

9. M. Walzer, Spheres of Justice, (Basil Blackwell, Oxford, 1983)

10. B. Roessler, Value of Privacy (Polity Press, Amsterdam, 2004)

11. E. Garver, Why pluralism now?, The Monist 73, 388-410 (1990)

12. D. Velleman, 'The Genesis of Shame', Philosophy and Public Affairs 30, 27-52 (2001)

13. B. Williams, Problems of the Self, (Cambridge University Press, Cambridge, 1973)

14. G. Marcel, Homo Viator, (Aubier, Editions Montaigne, Paris, 1944)

15. I. Berlin, Four Essays on Liberty, (Oxford University Press, Oxford, 1969)

16. R. Moran, Authority and Estrangement. An Essay on Self-Knowledge, (Princeton University Press, Princeton (NJ), 2001) 